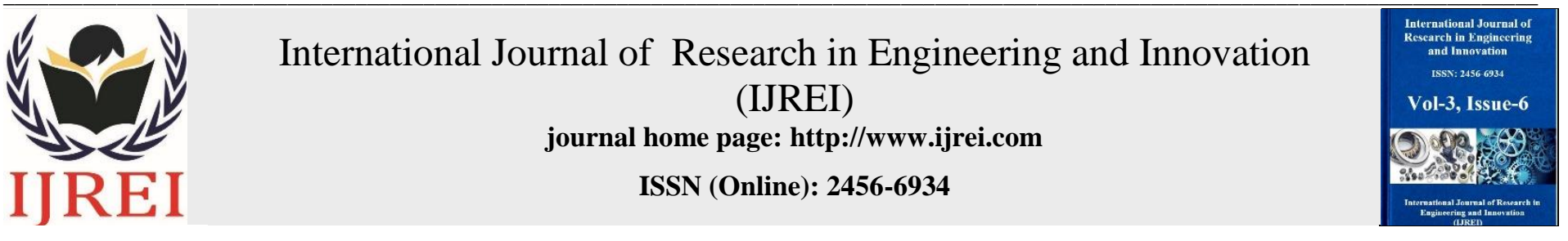

\title{
Optimization of process parameters and mechanical properties of hybrid fibre reinforced by epoxy resin by response surface methodology (RSM)
}

\author{
Ashok Kumar' ${ }^{1}$ Jitender Kumar², Deepak Juneja ${ }^{2}$ \\ ${ }^{I}$ M.Tech Scholar, Department of Mechanical Engineering, Geeta Engineering College, Panipat, India \\ ${ }^{2}$ Department of Mechanical Engineering, Geeta Engineering College, Panipat, India
}

\begin{abstract}
Natural fibers and synthetic fibers have several advantages that have made them particularly attractive to the automobile industry. These include relatively good mechanical strength, low density better thermal and acoustic insulation and low cost. According to the need the different type of fibers composites (Natural, synthetic and composite of natural and synthetic) can be reinforced.

In this work, there are 20 experiments are conducted to fabricate the hybrid (glass fiber and coir fiber) composite fiber with the help of design expert software and these fabricated composite fiber were tested according to ASTM standards and found the optimum and maximum tensile strength and strain of the composite fiber. Two quadratic model were given to correlate the process variables to the responses. The glass fiber is most significant factor for both the responses. The optimized input process parameters were found of glass fiber, coir fiber and filler are 100 gram of glass fiber, 40 gram of coir fiber and 80 gram of filler (Epoxy + Hardener) respectively. The optimized output responses value of tensile strength and strain were found $49.27 \mathrm{MPa}$ and $14.43 \%$ respectively.

Keywords: Natural Fiber, Synthetic fiber, tensile strength, Strain, Optimization

\section{Introduction}

A composite is combination of two materials in which one of the materials, called the reinforcing phase, is in the form of fibers, sheets, or particles, and is embedded in the other materials called the matrix phase. The reinforcing material and the matrix material can be metal, ceramic, or polymer. Composites typically have a fiber or particle phase that is stiffer and stronger than the continuous matrix phase and serve as the principal load carrying members. The matrix acts as a load transfer medium between fibers, and in less ideal cases where the loads are complex, the matrix may even have to bear loads transverse to the fiber axis. The matrix is more ductile than the fibers and thus acts as a source of composite toughness. The matrix also serves to protect the fibers from environmental damage before, during and after composite processing. When designed properly, the new combined material exhibits better strength than would each individual material. Composites are used not only for their structural properties, but also for electrical, thermal, tribological, and environmental applications. Life cycle environmental performance of natural fiber composites with glass fiber reinforced composites and found that natural fiber composites are environmentally superior in the specific applications studied. Natural fiber composites are likely to be environmentally superior to glass fiber composites in most cases [1]. The physical and mechanical behavior of banana fiber reinforced polymer composite and noticed that kraft mashed banana fiber material has better flexural strength. The tensile strength is detected maximum at $30 \mathrm{~mm}$ fiber length whereas the impact strength is noticed maximum at $40 \mathrm{~mm}$ length of fiber. Consolidation of $40 \%$ untreated banana fibers gives $20 \%$ rise in the tensile strength and $34 \%$ rise in impact strength [2]. Another effective method of surface chemical modification of natural fibers is graft copolymerization. Optimized vinyl grafted natural fibers, consisting of the orderly arrangement of grafted moieties, act as compatible reinforcing fibers with several resin systems to obtaining better fiber-matrix adhesion of the resulting biocomposites [3]. Cellulose fibers have been used for long time in the manufacture of various products such as rope, string, clothing, carpets and other decorative products. One of the major uses of kenaf fiber is to make a range of paper and cardboard products as a substitute for wood fibers which are the most abundantly used 
cellulose fibers. The most efficient cellulose fibers are those with high cellulose content coupled with a low micro-fibril angle in the range of $7-12^{0}$ to the fiber axis [4]. The plant fiber properties directly influence the physical parameters of the fiber-reinforced composites. Flax fiber properties are controlled by the molecular fine structure of the fibers which is affected by growing conditions and the fiber processing technique used [5]. Natural fibers are hygroscopic in nature and they absorb or release moisture depending on environmental conditions [6]. Fillers are used for a variety of reasons such as cost reduction, density control, improved processing, control of thermal expansion, optical effects, magnetic properties, thermal conductivity, electrical properties, and improved hardness and wear resistance, flame retardancy etc [7]. Depending upon the application and the type of property to be imparted to the composite, size of fibers are accordingly determined [8]. The mechanical properties of natural fiber based polymer composites are influenced by many factors such as fibers volume fraction, fiber length, fiber aspect ratio, fiber-matrix adhesion, fiber orientation [9]. The composite materials are successfully replacing the traditional materials due to lightweight, easy handle, renewable resources, nontoxic, high tensile strength [10]. 3-point flexural test to qualitatively assess such effects for 55, 60 and 65 weight percentages of E-glass fibers reinforced epoxy composites during cryogenic and after thawing conditions. The specimens were tested at a range of $0.5 \mathrm{~mm} / \mathrm{min}$ to $500 \mathrm{~mm} / \mathrm{min}$ crosshead speed to evaluate the sensitivity of mechanical response during loading at ambient and sub-ambient $\left(-80^{\circ} \mathrm{C}\right.$ temperature) [11]. The mechanical properties of banana fiber based epoxy composite have been studied and it was observed that the tensile strength is increased by $90 \%$ of the pseudo-stem banana fiber reinforced epoxy composite associated to virgin epoxy [12]. A systematic experimental design to find the parameters that can affect conductivity and strength can be employed by utilizing the response surface methodology (RSM) procedure coupled with central composite design (CCD) and further subjected to regression analysis. RSM reduces the number of required experimental runs to achieve a statistically validated result [13]. The mechanical properties, especially interfacial performances of the composites based on natural fibers due to the poor interfacial bonding between the hydrophilic natural fibers and the hydrophobic polymer matrices [14]. Jute fibers were treated with alkali (NAOH) solution and physic-chemical properties of jute fibers was investigated. The treatments were applied under ambient and elevated temperatures and high pressure steaming conditions. The results indicated that the uniaxial tensile strength increased by up to $65 \%$ for alkali-steam treatment. The treatments without steaming were not as effective [15]. The Tensile properties and scanning electron Microscope analysis of Bamboo/glass fibers Reinforced epoxy Hybrid composites were studied. The effect of alkali treatment of the bamboo fibers on these properties was also studied. It was observed that tensile properties of the hybrid composite increase with glass fiber content [16]. The influence of fiber length on the mechanical and physical properties of nonwoven short banana, random oriented fiber and epoxy composite have been investigated and they described that the tensile properties and percentage elongation of the composite attained a maximum in composite fabricated from $15 \mathrm{~mm}$ fiber length [17]. The composites material having $20 \%$ treated fiber loading possess maximum values for above-mentioned properties than untreated composites, $10 \%$ and also $30 \%$ treated fibers composites. The interfacial area having main role in influential the strength of polymer material since fiber procedures a separate interface with the matrix. The effects of this study uncovered that short zig-zag fiber composites with great rigidity and element mechanical properties might be effectively ready utilizing banana fiber as reinforcement in a polyurethane matrix inferred from castor oil. Composite materials reinforced by aluminum and synthetic fibers [18]. (Nylon and GFRP) were examined from the analysis of computational modal analysis [19-21]. In this work, Mathematical modelling was carried out by response surface method (RSM) and optimum value was opt with RSM results and optimize the input parameters (i.e. glass fiber, coir fiber and epoxy resin) and output responses (i.e. tensile strength and strain) for fabrication of hybrid composite fiber with the help of epoxy resin.

\section{Materials and Method}

In this work, glass fiber (synthetic) and coir fiber (natural) were used as shown in fig. 1 . The epoxy resins are being widely used for many advanced composites due to their many advantages such as excellent adhesion to wide variety of fibers, good performance at elevated temperatures and superior mechanical and electrical properties. In addition to that they have low shrinkage upon curing and good chemical resistance. Due to several advantages over other thermoset polymers as mentioned above, epoxy (LY 556) and hardener (HY951) was used as shown in fig.2.

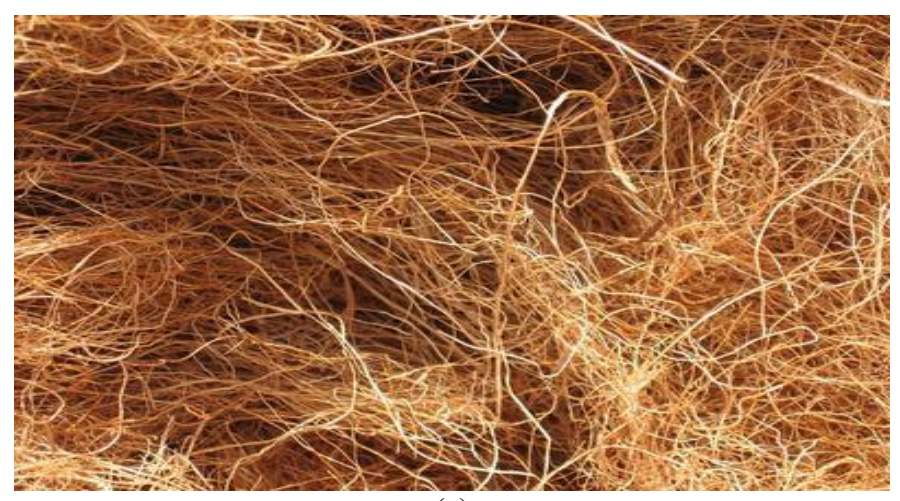

(a)

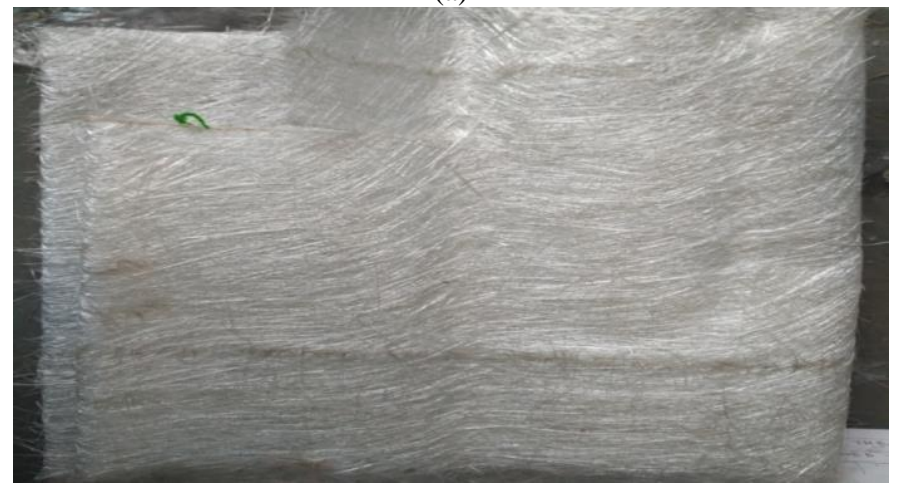

(b)

Figure 1: (a) Coir fiber, (b) Glass fiber 


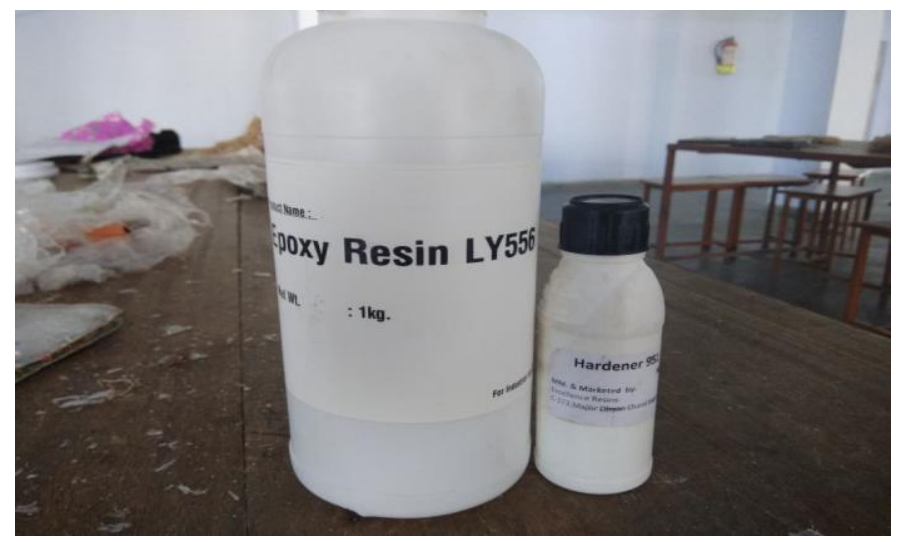

Figure 2: Epoxy (LY 556) and hardener (HY951)

Before making fiber plate, we need of design experiments, there are 20 experiments are taken for different fiber composition using design expert software. These composition are mentioned in table 1. According to this table maximum weight of glass fiber, Coir and filler (Epoxy LY556 + Hardener HY951) have been taken $100 \mathrm{gm}, 50 \mathrm{gm}$ and $100 \mathrm{gm}$ whereas minimum weight of glass fiber, Coir and filler (Epoxy LY556 + Hardener HY951) have been taken $60 \mathrm{gm}, 30 \mathrm{gm}$ and $60 \mathrm{gm}$.

In this work, glass fiber, epoxy and hardener were taken as reinforcement is collected from the local fiber shop and coir fiber was taken from local source. A mild steel mould having dimension $170 \times 110 \times 10 \mathrm{~mm}$ is used for composite fiber fabrication. One layer of glass fiber with epoxy and hardener are mixed and this mixture is poured in to the moulded base plate after that second layer of coir fiber was fed on to the glass fiber layer and then third layer of glass fiber again fed on the coir fiber and making sandwich of synthetic and natural fiber. After this process this die will be pressed by the hydraulic press with constant pressure $10 \mathrm{~kg} / \mathrm{cm} 2$ for 1 hour. A releasing agent is used to facilitate easy removal of the composite form the die after that composite fiber will be placed at room temperature for 72 hours. The composition and designation of the composites prepared for the design of experiments listed in table 1.

\section{Results and Discussion}

\subsection{Tensile strength}

The mechanical properties such as tensile strength of hybrid composite fiber (natural and synthetic fiber) with epoxy resin have been studied. There are 20 experiments were conducted by variation of fiber and epoxy mixing with the help of design expert software.

Fig. 3-5 shows the tensile strength and strain of composite fiber with increase fraction of coir and glass fibers. Weight of glass fiber with different parameters of epoxy resin have a significant effect on tensile strength of the composite fiber. Increase the glass fiber content shows a gradually increase in tensile strength. This behavior can be explained by straight nature of long glass fiber. This straight behavior of glass fiber is help to properly align in longitudinal direction and thus results in in increases in tensile strength. 80 gram glass fiber, 40 gm coir fiber and 100 gram (epoxy+hardener) shows the maximum tensile strength of 57 $\mathrm{MPa}$. Whereas 60 gram glass fiber, 50 gm coir fiber and 100 gram (epoxy+hardener) shows minimum tensile strength of $31 \mathrm{MPa}$.

Table 1: Input processing parameters and their responses

\begin{tabular}{|c|c|c|c|c|c|}
\hline Run & $\begin{array}{c}\text { A:Glass fiber } \\
(\mathrm{gm})\end{array}$ & $\begin{array}{c}\text { B:Coir } \\
(\mathrm{gm})\end{array}$ & $\begin{array}{c}\text { C:Filler (LY556+HY951) } \\
(\mathrm{gm})\end{array}$ & $\begin{array}{c}\text { Tensile Strength } \\
(\mathrm{MPa})\end{array}$ & $\begin{array}{c}\text { Strain } \\
(\%)\end{array}$ \\
\hline 1 & 100 & 50 & 60 & 46 & 14 \\
\hline 2 & 100 & 30 & 100 & 53 & 17 \\
\hline 3 & 60 & 50 & 60 & 34 & 10 \\
\hline 4 & 80 & 40 & 80 & 37 & 9 \\
\hline 5 & 80 & 40 & 80 & 57 & 11 \\
\hline 6 & 100 & 40 & 80 & 38 & 11 \\
\hline 7 & 80 & 40 & 80 & 41 & 10 \\
\hline 8 & 80 & 30 & 80 & 34 & 12 \\
\hline 9 & 80 & 40 & 80 & 32 & 11 \\
\hline 10 & 60 & 30 & 100 & 32 & 16 \\
\hline 11 & 100 & 50 & 100 & 31 & 10 \\
\hline 12 & 60 & 40 & 80 & 35 & 11 \\
\hline 13 & 60 & 50 & 100 & 42 & 12 \\
\hline 14 & 80 & 40 & 60 & 34 & 10 \\
\hline 15 & 80 & 40 & 100 & 39 & 11 \\
\hline 16 & 80 & 40 & 80 & 38 & 12 \\
\hline 17 & 80 & 50 & 80 & 44 & 14 \\
\hline 18 & 100 & 30 & 60 & 32 & 10 \\
\hline 19 & 60 & 30 & 60 & & \\
\hline 20 & 80 & 40 & 80 & & 34 \\
\hline
\end{tabular}




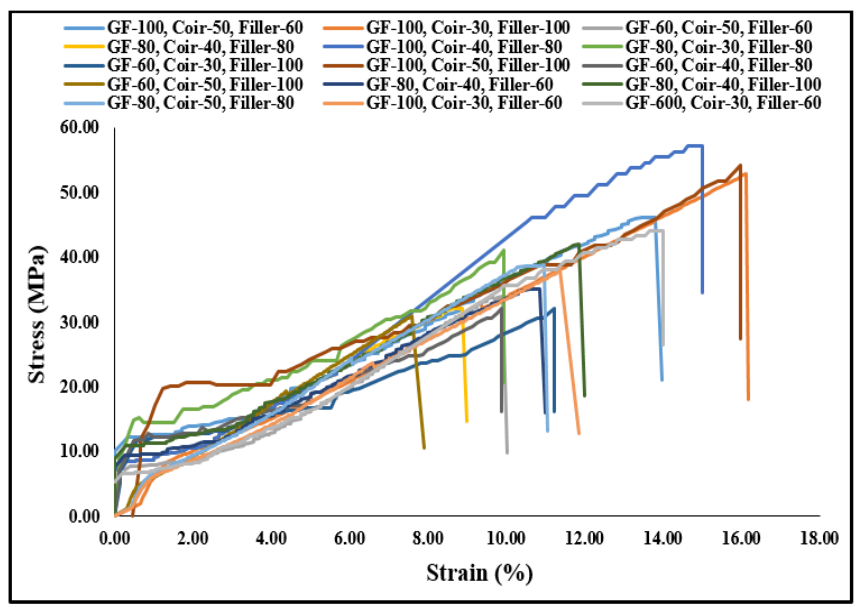

Figure 3: Stress strain diagram for composite fiber reinforced by epoxy resin

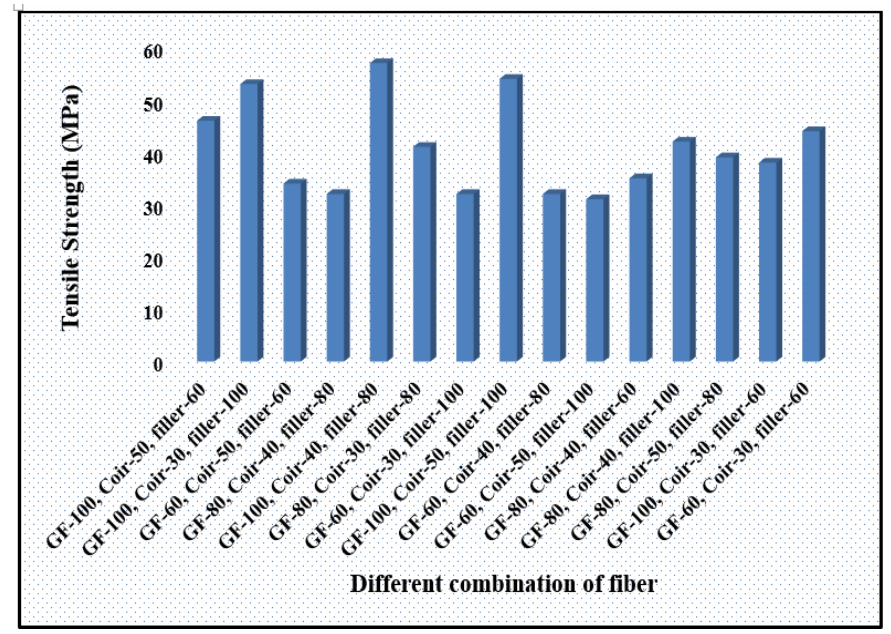

Figure 4: Comparison of tensile strength and different combination of fiber

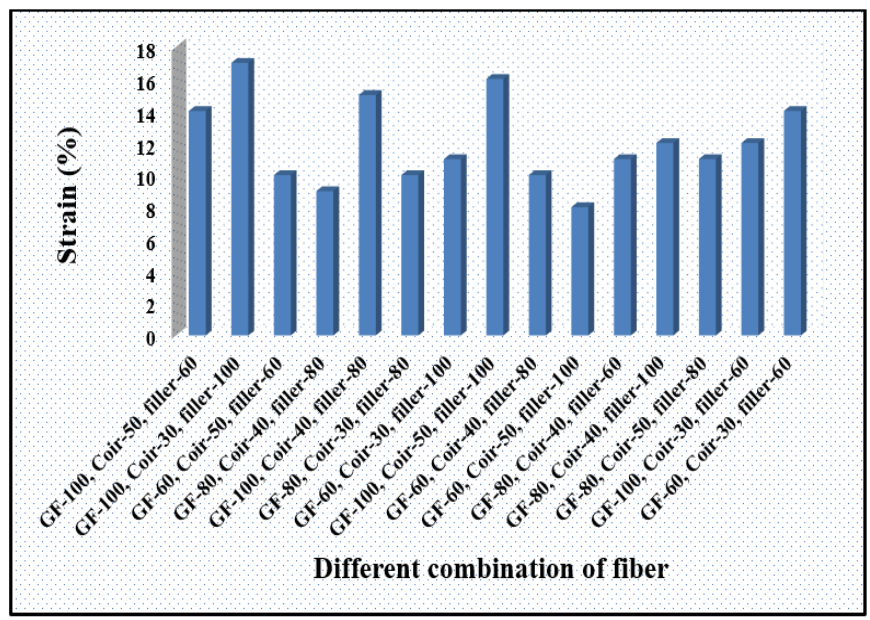

Figure 5: Comparison of strain and different combination of fiber

Similarly, when the weight of coir fiber is increases than the tensile strength of composite fiber is decreases, because the curly behavior of coir fiber is constrains to long fibers to properly align in longitudinal direction and thus results in decreases in tensile strength. When the percentage of glass fiber increases in composite then high energy is required to break the specimen, so when the fiber loading increases, more energy can be dissipated.

\subsection{Response surface Methodology}

Response surface methodology is as set of statistical and mathematical techniques which will be useful to develop the model, optimize and analyzed the engineering problems. Is also have many application in the field of development and design. It's a valuable tool for constructing and optimizing the models [22].The glass fiber, coir fiber and filler weight (Epoxy and hardener) are the variables selected for our experimental investigation. The different factor and their levels for this investigation as shown in table 1 . Now, there is correlation between an input parameters and output responses were given by

$$
\mathrm{Y}=\mathrm{F}\left(\mathrm{x}_{1}, \mathrm{x}_{2}, \mathrm{x}_{3} \ldots \ldots \mathrm{x}_{\mathrm{n}}\right)+\varepsilon
$$

Where $\varepsilon$ represent the noise or error observed in the output response $(\mathrm{Y})$. If we denote expected response to be $\mathrm{E}(\mathrm{Y})=\mathrm{F}\left(\mathrm{x}_{1}\right.$, $\mathrm{x}_{2}, \mathrm{x}_{3} \ldots \ldots . \mathrm{x}_{\mathrm{n}}$ ) then the surface represented by

$$
\eta=F\left(x_{1}, x_{2}, x_{3} \ldots \ldots x_{n}\right)
$$

The variable $\left(\mathrm{x}_{1}, \mathrm{x}_{2}, \mathrm{x}_{3} \ldots \ldots \mathrm{x}_{\mathrm{n}}\right.$ are called normal variable.

\subsection{Analysis of variance (ANOVA)}

Analysis of variance (ANOVA) is used to investigate the influence of process parameters on the responses characteristics. The purpose of ANOVA test is to determine the significance of process parameters which affect the mechanical properties of composite fiber. Table 2-3, represents the results of analysis of variance and suggested that the glass fiber is the most significant factor. The F-test (Fisher's test) may also be used to determine which process parameter has a significant effect on the mechanical properties.

\subsection{Developing a mathematical model}

The experimental results were obtained and analyzed to produce regression model. The statistical software design expert suggested second order quadratic regression surface model for predicting the optimum conditions for the fabricated hybrid composite. The empirical relationship was developed for the response variable i.e. ultimate tensile strength, and strain of composite fiber under the input processing parameters i.e. glass fiber, coir fiber and filler (Epoxy and hardener) and found best fit model in terms of equations. The mathematical empirical relationship for tensile strength, and strain are as follow.

Tensile Strength $=215.73-3.25 \mathrm{~A}-1.9 \mathrm{~B}-0.70 \mathrm{C}+0.0125 \mathrm{AB}$

$$
-0.0118 \mathrm{AC}+0.0012 \mathrm{BC}+0.0136 \mathrm{~A}^{2}+0.009 \mathrm{~B}^{2}-0.0012 \mathrm{C}^{2}
$$


Strain $=73.91-1.085 \mathrm{~A}-0.132 \mathrm{~B}-0.526 \mathrm{C}+0.005 \mathrm{AB}+$

$0.00375 \mathrm{AC}-0.00125 \mathrm{BC}+0.0043 \mathrm{~A}^{2}-0.0027 \mathrm{~B}^{2}+0.0018 \mathrm{C}^{2}$

Where A, B and C are the glass fiber, Coir and filler (Epoxy +
Hardener) weight respectively, and $\mathrm{A}^{2}, \mathrm{~B}^{2}$, and $\mathrm{C}^{2}$ are the square and interaction terms in the above equations, positive coefficient have positive effect on tensile stress and strain, whereas negative coefficient will decrease the strength of the hybrid composite material.

Table 2: Analysis of variance (ANOVA) for tensile strength for composite fiber

\begin{tabular}{|c|c|c|c|c|c|c|}
\hline Source & Sum of Squares & $\mathrm{df}$ & Mean Square & F-value & p-value & \\
\hline Model & 982.67 & 9 & 109.19 & 5.32 & 0.0076 & significant \\
\hline A-Glass fiber & 562.5 & 1 & 562.5 & 27.43 & 0.0004 & \\
\hline B-Coir & 1.6 & 1 & 1.6 & 0.078 & 0.7857 & \\
\hline C-Filler & 22.5 & 1 & 22.5 & 1.1 & 0.3196 & \\
\hline AB & 50 & 1 & 50 & 2.44 & 0.1495 & \\
\hline AC & 180.5 & 1 & 180.5 & 8.8 & 0.0141 & \\
\hline BC & 0.5 & 1 & 0.5 & 0.0244 & 0.879 & \\
\hline $\mathrm{A}^{2}$ & 81.82 & 1 & 81.82 & 3.99 & 0.0737 & \\
\hline $\mathrm{B}^{2}$ & 2.51 & 1 & 2.51 & 0.1222 & 0.7339 & \\
\hline $\mathrm{C}^{2}$ & 0.8182 & 1 & 0.8182 & 0.0399 & 0.8457 & \\
\hline Residual & 205.08 & 10 & 20.51 & & & \\
\hline Lack of Fit & 173.58 & 5 & 34.72 & 5.51 & 0.0422 & Not significant \\
\hline Pure Error & 31.5 & 5 & 6.3 & & & \\
\hline Cor Total & 1187.75 & 19 & & & & \\
\hline
\end{tabular}

Table 3: Analysis of variance (ANOVA) for strain for composite fiber

\begin{tabular}{|c|c|c|c|c|c|c|}
\hline Source & Sum of Squares & df & Mean Square & F-value & p-value & \\
\hline Model & 95.45 & 9 & 10.61 & 9.87 & 0.0007 & significant \\
\hline A-Glass fiber & 44.1 & 1 & 44.1 & 41.04 & $<0.0001$ & \\
\hline B-Coir & 2.5 & 1 & 2.5 & 2.33 & 0.1582 & \\
\hline C-Filler & 0.9 & 1 & 0.9 & 0.8376 & 0.3816 & \\
\hline $\mathrm{AB}$ & 8 & 1 & 8 & 7.45 & 0.0212 & \\
\hline $\mathrm{AC}$ & 18 & 1 & 18 & 16.75 & 0.0022 & \\
\hline $\mathrm{BC}$ & 0.5 & 1 & 0.5 & 0.4653 & 0.5106 & \\
\hline $\mathrm{A}^{2}$ & 8.2 & 1 & 8.2 & 7.64 & 0.02 & \\
\hline $\mathrm{B}^{2}$ & 0.2045 & 1 & 0.2045 & 0.1904 & 0.6719 & \\
\hline $\mathrm{C}^{2}$ & 1.45 & 1 & 1.45 & 1.35 & 0.2717 & \\
\hline Residual & 10.75 & 10 & 1.07 & & & \\
\hline Lack of Fit & 5.25 & 5 & 1.05 & 0.9537 & 0.5201 & not significant \\
\hline Pure Error & 5.5 & 5 & 1.1 & & & \\
\hline Cor Total & 106.2 & 19 & & & & \\
\hline
\end{tabular}

The developed models was tested using ANOVA method with the help of design expert software. The ANOVA results for tensile strength and strain for hybrid composite fiber are shown in table 2-3. All models gives the highly significant fisher's F value which shows that the model adequately representing the relationship between input process parameters and response. The fisher's F value of the tensile strength for hybrid composite fiber was found 5.32, whereas the fisher's $F$ value for the strain was 9.87. The $P$ value is very small for tensile strength $\mathrm{P}(0.0076)$ which represented that the generated models have only $0.76 \%$ chance that a model Fisher's value could occur due to noise, whereas developed model for strain have only $0.07 \%$ chance that a model Fisher's $F$ value could occur due to noise. For tensile strength model, the residual error value (205.08) should be the sum of lack of fit (173.58) and pure error (31.5). By this column of fit summary recommended quadratic model is statically significant for analyzing the tensile strength of hybrid composite fiber.

\subsection{Optimization of input process parameters}

The contour plot and 3D response surface graph are made based on the model developed by considering the optimum process parameters. The optimum tensile strength and strain value of hybrid composite fiber is exhibited by the peak of response surface as shown in fig. 6-7. The effect of straight behavior of glass fiber on hybrid composite fiber is to increase the tensile strength whereas curly behavior of coir fiber is decrease the tensile strength as shown in fig. 8-9. When the glass fiber is increases than the tensile strength also increases whereas tensile strength is decreases when coir fiber increases. The maximum tensile strength ( $57 \mathrm{MPa}$ ) was found at 80 gram glass fiber, $40 \mathrm{gm}$ coir fiber and 100 gram (epoxy+hardener) as shown in fig. 4. 

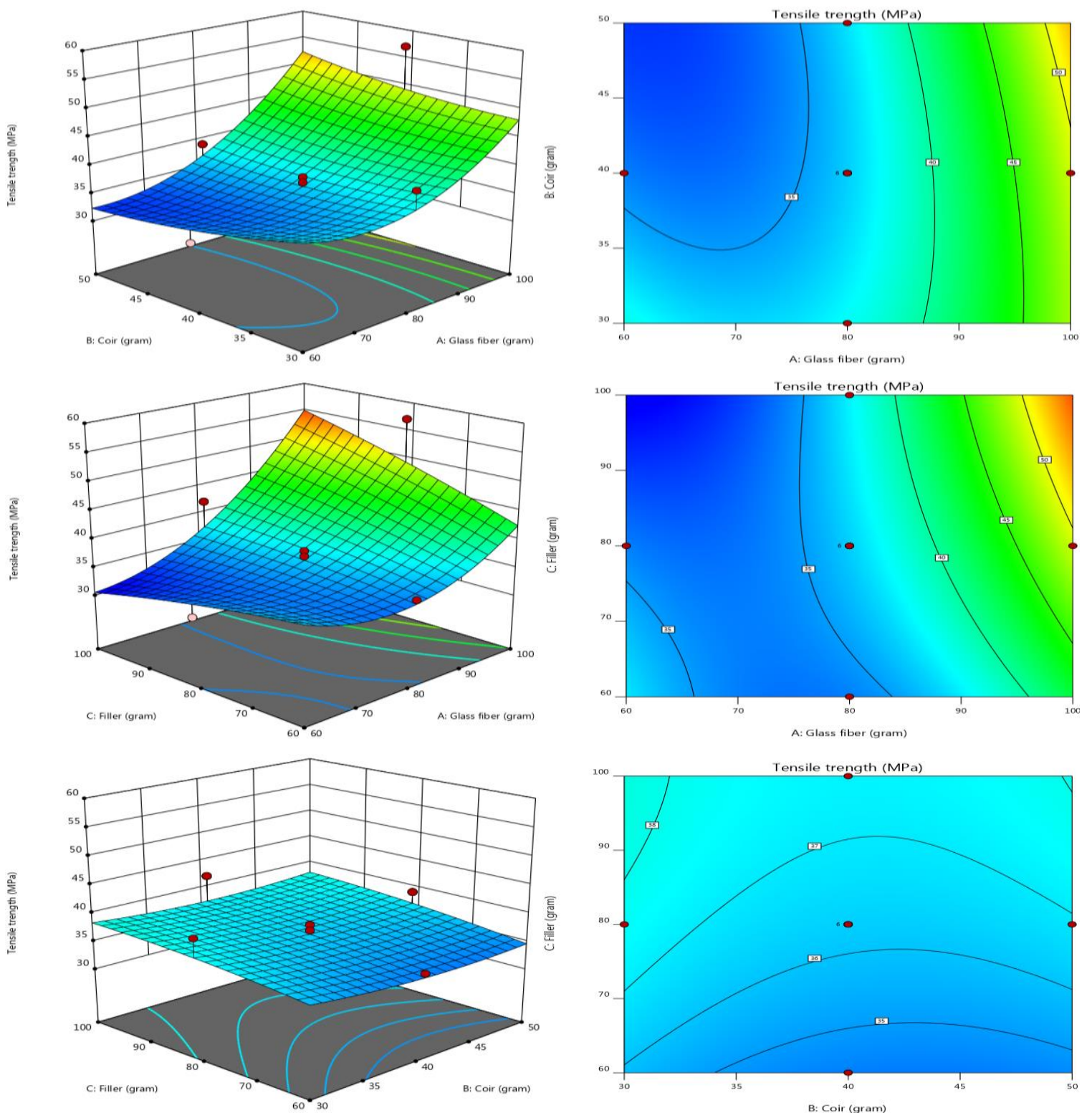

Figure 6: 3D response surface plot and contour plot for tensile strength for hybrid composite fiber
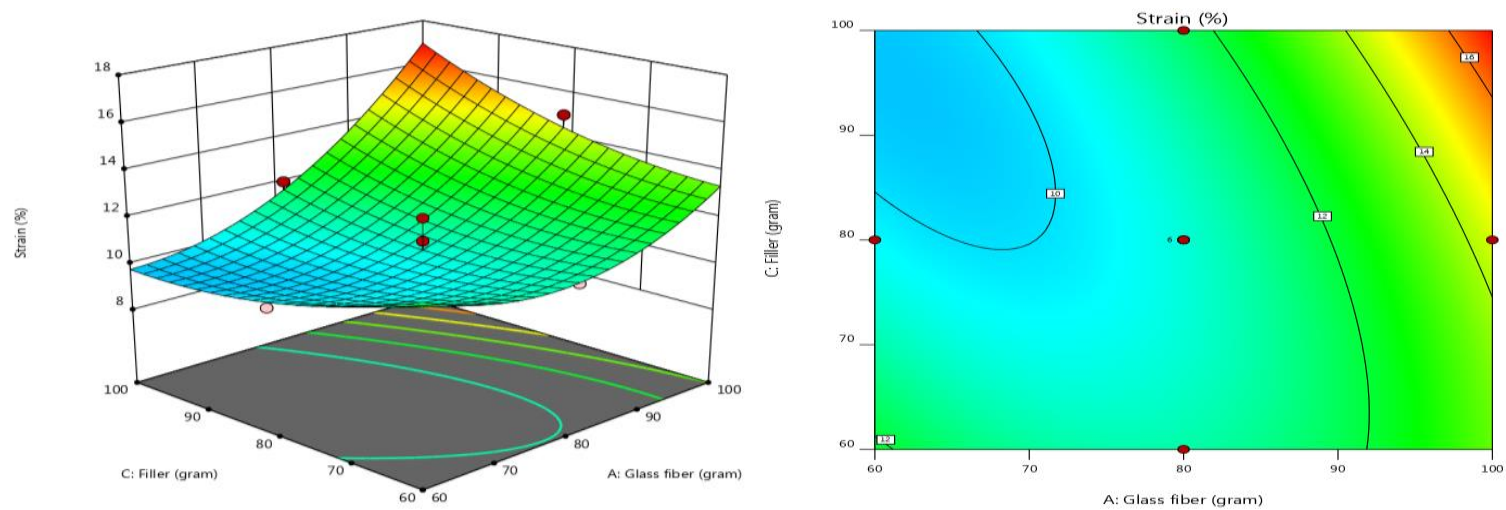

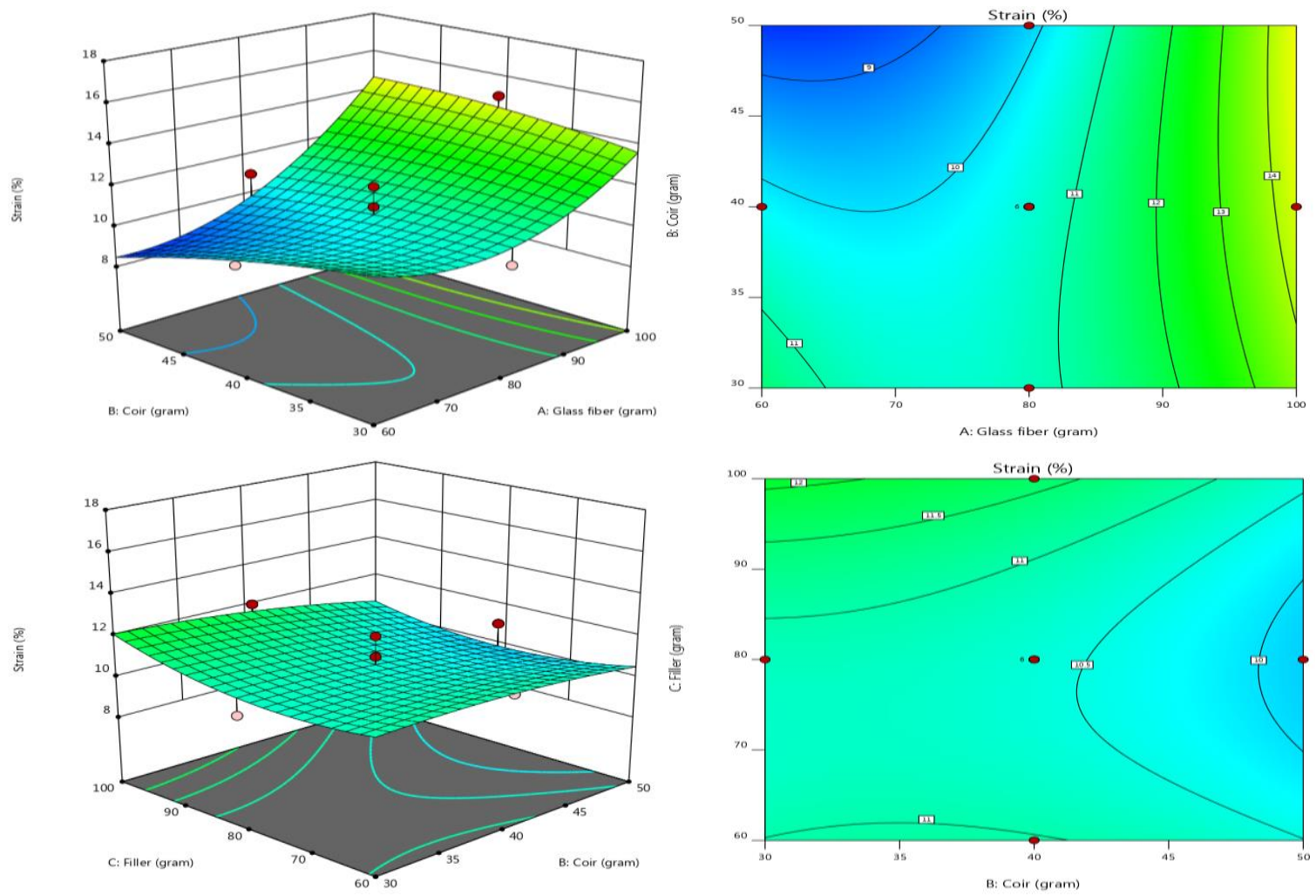

Figure 7: 3D response surface plot and contour plot for percentage strain for hybrid composite fiber
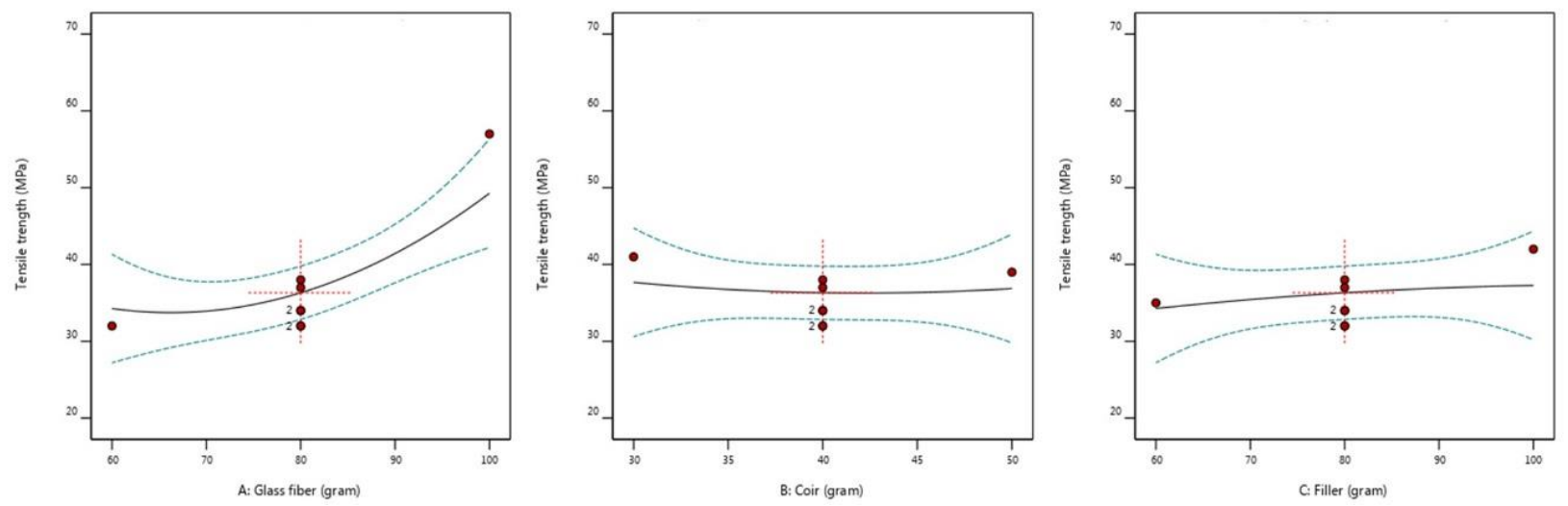

Figure 8: Variation of Tensile strength and input processing parameters of hybrid composite fiber
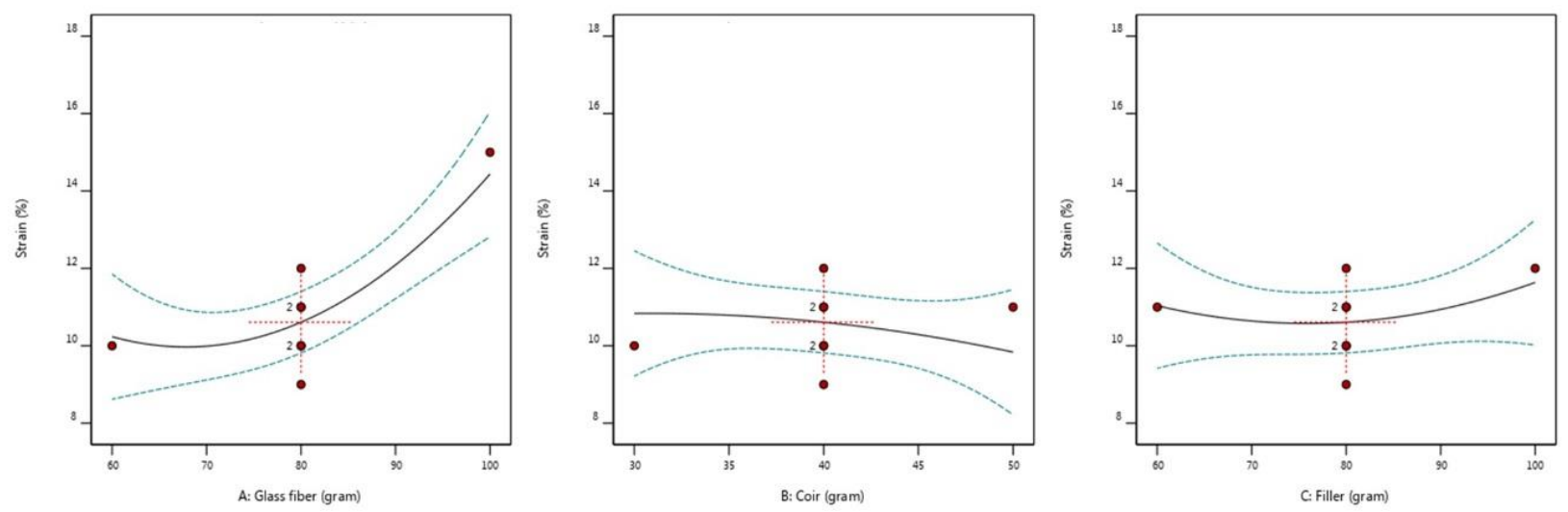

Figure 9: Variation of strain and input processing parameters of hybrid composite fiber 
The ramp report and optimized contour plot as shown in fig. 10 are displayed in which the individual response graph is given for better understanding. The red dot and grey dot is mentioned on the ramp report which indicate that the optimized input and output responses of the composite fiber. The optimized input process
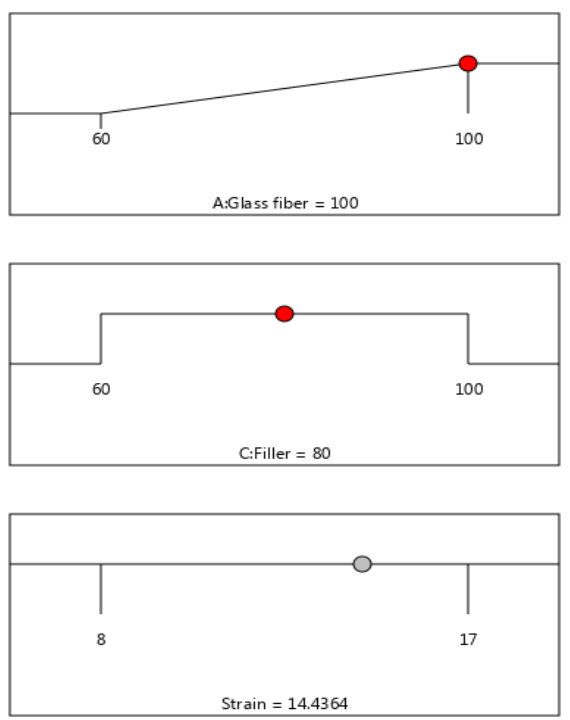

Figure 10: Optimize value of input and their output responses of composite fiber parameters value of glass fiber, coir fiber and filler are 100 gram, 40 gram and 80 gram respectively whereas optimized output responses value of tensile strength and strain are $49.27 \mathrm{MPa}$ and $14.43 \%$ respectively.
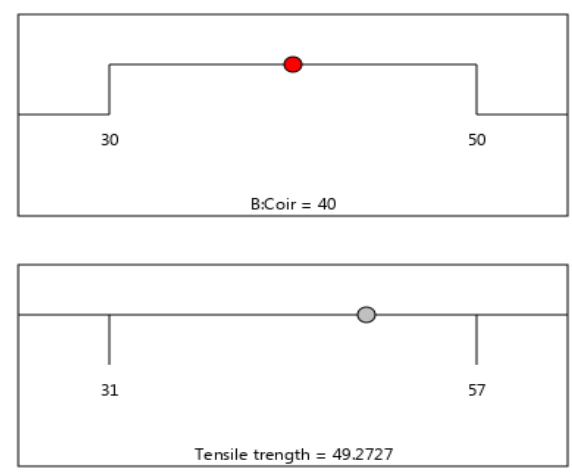

Desirability $=1.000$ Solution 1 out of 100

\section{Conclusions}

In this work, there are 20 experiments are conducted to fabricate the hybrid (glass fiber and coir fiber) composite fiber with the help of design expert software and these fabricated composite fiber were tested according to ASTM standards and found the optimum and maximum tensile strength and strain of the composite fiber. The following conclusion are made during this work.

- The effect of glass fiber, coir fiber and filler weight were successfully studied using response surface methodology.

- Two quadratic model were given to correlate the process variables to the responses. The glass fiber is most significant factor for both the responses.

- The maximum tensile strength and strain were found $54 \mathrm{MPa}$ and $16 \%$ respectively at input parameters of 100 gram of glass fiber, 50 gram of coir fiber and 100 gram of filler (Epoxy + Hardener).

- The optimized input process parameters were found of glass fiber, coir fiber and filler are 100 gram of glass fiber, 40 gram of coir fiber and 80 gram of filler (Epoxy + Hardener) respectively.

- The optimized output responses value of tensile strength and strain were found $49.27 \mathrm{MPa}$ and $14.43 \%$ respectively.

\section{References}

[1] S.V. Joshi, L.T. Drzal, A.K. Mohanty, S. Arora "The mechanical properties of vinylester resin matrix composites reinforced with alkali-treated jute fibres" Part A 32 (2001) 119-127.
[2] Laban B. G., Corbiere-Nicollier T., Leterrier Y., Lundquist L., Manson J. A E., Jolliet O., Life Cycle Assessment of Biofibers Replacing Glass Fibers as Reinforcement in plastics, Resources Convertion and Recycling, 33(2001), pp. 267-287.

[3] Mishra, S., M. Misra, S.S. Tripathy, S.K. Nayak and A.K. Mohanty. 2001b. Graft copolymerization of acrylonitrile on chemically modified sisal fibers. Macromolecular Material and Engineering 286(2):107-113.

[4] Bos, H.L., Van Den Oever, M.J.A., O.C.J.J. (2002), Tensile and compressive properties of flax fibers for natural fiber reinforced composites. Materials Science, 37: 1683-1692

[5] Jähn, A., M.W. Schröder, M. Füting, K. Schenzel and W. Diepenbrock. 2002. Characterization of alkali treated flax fibers by means of FT Raman spectroscopy and environmental scanning electron microscopy. Spectrochimica Acta, Part A: Molecular and Biomolecular Spectroscopy 58(10):2271-2279.

[6] Powell, T., S. Panigrahi, J. ward, L.G. Tabil, W.J. Crerar and S. Sokansanj. 2002. Engineering properties of flax fiber and flax fiber-reinforced thermoplastic in rotational molding, Paper No. MBSK 02-205. ASAE, 2905 Niles Road, St. Joseph, MI 49085-9659 USA.

[7] Kim J., Kang P.H. and Nho Y.C., (2004). Positive temperature coefficient behavior of polymer composites having a high melting temperature, Journal of Applied Polymer Science, 92(1), pp. 394-401.

[8] Torres F.G., Diaz R.M., Morphological characterisation of natural fibre reinforced thermoplastics (NFRTP) processed by extrusion, compression and rotational moulding, Polymers and Polymer Composites 12 (8) (2004) pp-705-718.

[9] Kahraman R., Abbasi S. and Abu-Sharkh B., (2005). Influence of Epolene G3003 as a Coupling Agent on the Mechanical Behavior of Palm FiberPolypropylene Composites, International Journal of Polymeric Materials, 54(6), pp. 483-503

[10] F.G. Torres and M.L.Cubillas,"Study of the interfacial properties of natural fibre reinforced polyethylene", Polymer Testing 24, (2005), pp. 694- 698.

[11] Ray, B. C. (2006). Loading Rate Sensitivity of Glass Fiber-Epoxy Composite at Ambient and Sub-ambient Temperatures. Journal of Reinforced Plastics and Composites, 25(3), 329-333. 
[12] Maleque M. A., Belal F. Y., Sapuan S. M., Mechanical Properties Study of Pseudo-Stem Banana Fiber Reinforced Epoxy Composite, The Arabian Journal for Science and Engineering, 32 (2007), pp. 359-364.

[13] Wang B, Panigrahi S, Tabil L, Crerar W. Pre-treatment of flax fibers for use in rotationally molded biocomposites journal of Reinforced Plastics and Composites, 2007;26 (5) :447-463.

[14] Yan $\mathrm{Li}$, Chunjing $\mathrm{Hu}$, Yehong Yu "Interfacial studies of sisal fiber reinforced high density polyethylene (HDPE) composites" Part A 39 (2008) 570-578.

[15] Prosenjit Saha, Suvendu Manna, Sougata Roy Chowdhury, Ramkrishna Sen, Debasis Roy, Basudam Adhikari "Enhancement of tensile strength of lignocellulosic jute fibers by alkali-steam treatment" 101 (2010) 3182-3187.

[16] A.Alavudeen,M. Thiruchitrambalam, N.Venkateshwaran and A.Athijayamani "Review of natural fiber reinforced Woven composite" Advances in Material science, volume -27: 2011, 146-150

[17] Sumaila M., Amber I., Bawa M., Effect of Fiber Length on the Physical and Mechanical Properties of Random Oriented, Nonwoven Short banana (Musa Balbisiana) Fiber/Epoxy Composite, Asian Journal of Natural \& Applied Sciences, 2 (2013), pp. 39-49.
[18] Prasanna G. V., Subbaiah, K. V., Modification, Flexural, Impact, Compressive Properties \& Chemical Resistance of Natural Fibers Reinforced Blend Composites, Malaysian Polymer Journal, 8 (2013), pp. 38-44.

[19] Husain Mehdi Rajan Upadhyay, Rohan Mehra, Adit, Modal Analysis of Composite Beam Reinforced by AluminiumSynthetic Fibers with and without Multiple Cracks Using ANSYS, International journal of Mechanical Engineering, 2014, 4 (2), 70-80.

[20] Husain Mehdi, Anil Kumar, Arshad Mehmood, Manoj Saini, Experimental Analysis of Mechanical Properties of Composite Material Reinforced by Aluminium-Synthetic Fibers, International journal of Mechanical Engineering, 2014, 2 (2), 59-69.

[21] Husain Mehdi, Arshad Mehmood, Theoretical Modelling and Experimental Investigation on Mechanical Properties of Natural Fiber Reinforced By Epoxy Resin Matrices, Journal of Materials Science \& Surface Engineering, 2019, 6(5): 867-871

[22] Myers RH, Montgomery DC Response surface methodology: process and product optimization using designed experiments.Wiley, (1995) New York.

Cite this article as: Ashok Kumar, Jitender Kumar, Deepak Juneja, Optimization of process parameters and mechanical properties of hybrid fibre reinforced by Epoxy Resin by response surface methodology (RSM), International Journal of Research in Engineering and Innovation Vol-3, Issue-6 (2019), 399-407. https://doi.org/10.36037/IJREI.2019.3608 